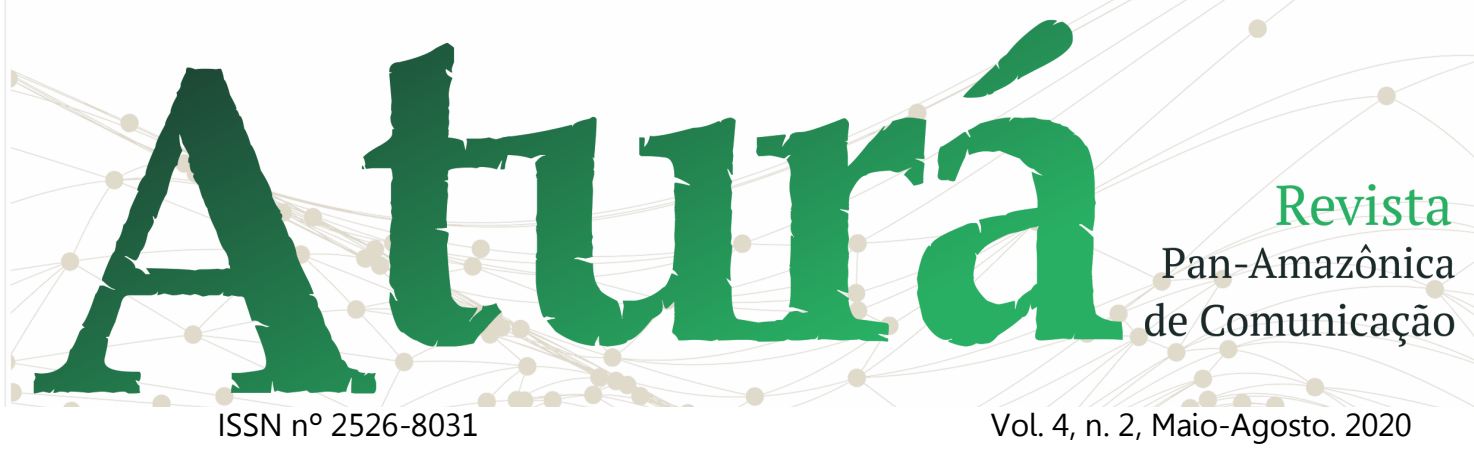

DOI: http://dx.doi.org/10.20873/uft.2526-8031.2020v4n2p227

\title{
PROBLEMATIZAÇÕES TEÓRICAS SOBRE A DIVERSIDADE CULTURAL, SEXUAL E DE GÊNERO DO CURRÍCULO DE EDUCAÇÃO BÁSICA DE PALMAS
}

Theoretical problematizations about the cultural, sexual and gender diversity of the basic education curriculum of Palmas

Problematizaciones teóricas sobre la diversidad cultural, sexual y de género del currículo de educación básica de Palmas

\section{Romário Rocha Nascimento, Universidade Federal do Tocantins ${ }^{1}$ Amanda Maurício Pereira Leite, Universidade Federal do Tocantins ${ }^{2}$}

\section{RESUMO}

O rito de passagem de preparação da criança para a vida adulta requer uma melhor atenção sobre a relevância da diversidade. Naturalmente o debate, seja ele sobre gênero, cultura ou sexualidade, torna-se mais do que indispensável, visto que as problematizações vão além do que é padronizado em diretrizes educacionais. Dessa forma, o presente estudo busca analisar e problematizar concepções teóricas acerca do currículo proposto pela Secretaria Municipal de Educação do Município de Palmas, tendo como base as teorias sobre diversidade cultural, sexual e de gênero para a educação básica. Como problema, questionamos se a diversidade se faz presente no currículo e o que os teóricos, como Foucault (1988); Da Silva (1999); Felipe (2006); Maia; Rocha; Vizolli (2017); Alecrim (2017); Lionço (2018), narram sobre, considerando que a descentralização do sujeito é calcada pela característica subjetiva de ser. $\mathrm{O}$ estudo mostra a existência de conflitos entre o que defende o currículo do Município de Palmas/TO e os apontamentos das teorias póscríticas em relação à temática de gênero e sexualidade.

PALAVRAS-CHAVE: Currículo. Diversidade. Educação básica.

\footnotetext{
${ }^{1}$ Mestrando em Comunicação e Sociedade, PPGCOM-UFT. Bacharel em Administração. E-mail: admrocha13@gmail.com.

${ }^{2}$ Mestre e doutora em Educação. Professora no Programa de Pós-Graduação em Comunicação e Sociedade (UFT). E-mail: amandaleite@mail.uft.edu.br.
} 


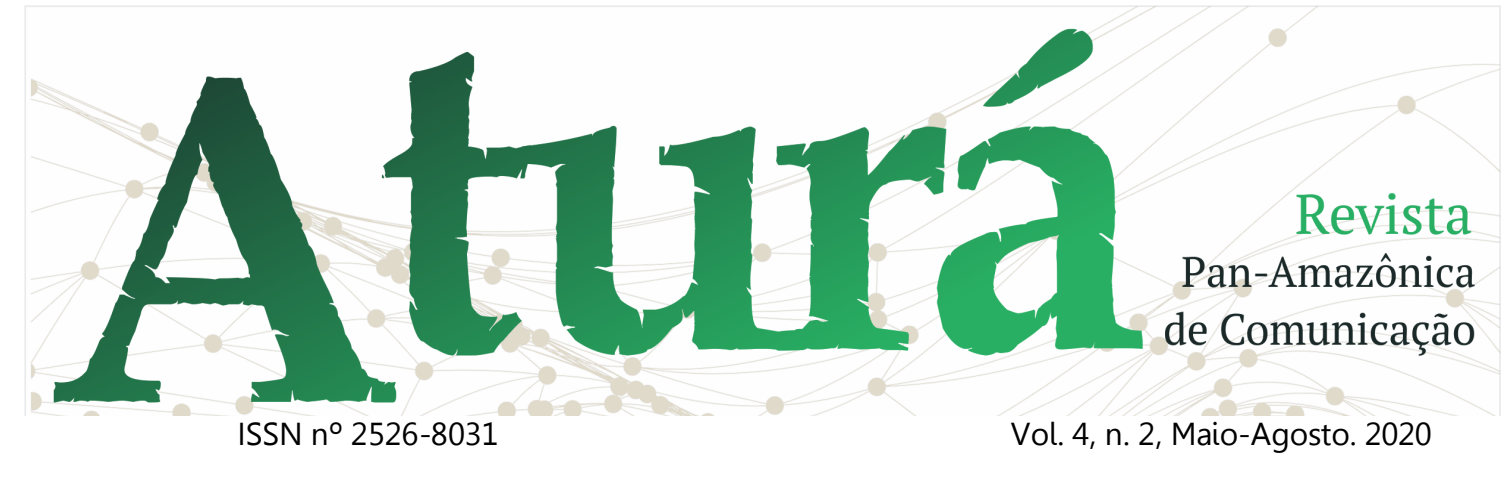

DOI: http://dx.doi.org/10.20873/uft.2526-8031.2020v4n2p227

\begin{abstract}
The rite of passage of preparation of the child for adult life requires better attention to the relevance of diversity. Naturally the debate, whether on gender, culture or sexuality, becomes more than indispensable, since the problems go beyond what is standardized in educational guidelines. Thus, this study seeks to analyze and problematize theoretical conceptions about the curriculum proposed by the Municipal Secretariat of Education of the Municipality of Palmas, based on theories about cultural, sexual and gender diversity for basic education. As a problem, we question whether diversity is present in the curriculum and what theorists, such as Foucault (1988); Da Silva (1999); Felipe (2006); Maia; Rocha; Vizolli (2017); Alecrim (2017); Lionço (2018), tell about, considering that the decentralization of the subject is based on the subjective characteristic of being. The study shows the existence of conflicts between what defends the curriculum of the Municipality of Palmas-TO and the notes of post-critical theories in relation to the theme of gender and sexuality.
\end{abstract}

KEYWORDS: Curriculum. Diversity. Basic education.

\title{
RESUMEN
}

El rito de paso de la preparación del niño para la vida adulta requiere una mayor atención a la relevancia de la diversidad. Naturalmente, el debate, ya sea sobre el género, la cultura o la sexualidad, se hace más que indispensable, ya que los problemas van más allá de lo que está normalizado en las directrices educativas. Así, este estudio busca analizar y problematizar las concepciones teóricas sobre el currículo propuesto por la Secretaría Municipal de Educación del Municipio de Palmas, a partir de las teorías sobre la diversidad cultural, sexual y de género para la educación básica. Como problema, cuestionamos si la diversidad está presente en el currículo y lo que cuentan teóricos como Foucault (1988); Da Silva (1999); Felipe (2006); Maia; Rocha; Vizolli (2017); Alecrim (2017); Lionço (2018), considerando que la descentralización del sujeto se basa en la característica subjetiva del ser. El estudio muestra la existencia de conflictos entre lo que defiende el currículo del Municipio de Palmas-TO y las notas de las teorías post-críticas en relación con el tema de género y sexualidad.

PALABRAS CLAVE: Plan de estudios. Diversidad. Educación básica.

Recebido em: 12.02.2020. Aceito em: 14.04.2020. Publicado em: 01.05.2020. 


\section{A \\ ISSN n 2526-8031 \\ Vol. 4, n. 2, Maio-Agosto. 2020 \\ Revista \\ Pan-Amazônica \\ de Comunicação \\ DOI: http://dx.doi.org/10.20873/uft.2526-8031.2020v4n2p227}

\section{Introdução}

Apesar do avanço democrático em relação a participação e o respeito às diferenças dentro da sociedade ainda há muito que refletir e agir em relação a lógica expressiva da diversidade dentro do contexto escolar. A escola como espaço social e o currículo como instrumento condicionado de princípios, regras, roteiros e diretrizes, são também repletos de concepções que, através de experiências sociais, podem ser problematizados na guia de valores e ideologias. Ao longo do tempo o currículo da educação básica passou por inúmeras fases, adaptações e mudanças, reguladas especialmente pelo Governo através de leis e diretrizes de educação.

Os direcionamentos do currículo no âmbito escolar foram mudando de acordo com fundamentos teóricometodológicos e práticas de professores, contudo, os eixos onde se aborda sexualidade, cultura e gênero ainda são muito sensíveis ao debate. Se colocado em evidência a perspectiva social, a abordagem construtiva do currículo passaria por inúmeras indagações e expandiria, porém, ainda é restrita. Nesse pensamento questionamos como as concepções, problematizações e construções teóricas têm a colaborar com essa premissa.

Considerando a complexidade do processo de avaliação curricular do atual debate sobre diversidade, a investigação desse estudo parte da seguinte questão: Quais as concepções teóricas sobre diversidade cultural, sexual e de gênero na educação básica no currículo proposto pela Secretaria Municipal de Educação do Município de Palmas/TO? Para responder - questionamento o objetivo deste estudo consiste em analisar, por meio de abordagens teóricas, o texto do Plano Municipal de Educação do município de Palmas para verificar até que ponto o discurso sobre diversidade cultural, sexual e de gênero se (des)encontram. 


\section{A \\ ISSN n² 2526-8031 \\ Vol. 4, n. 2, Maio-Agosto. 2020 \\ Revista \\ Pan-Amazônica \\ de Comunicação \\ DOI: http://dx.doi.org/10.20873/uft.2526-8031.2020v4n2p227}

A escola tem um grande papel na sociedade, nela os indivíduos aprendem de forma sistemática os conceitos sobre ter uma vida ética e emancipada. Já a formulação do currículo entra em constante confronto e atravessa a linha de vários princípios e representações. As implicações pedagógicas na construção do aluno como ser social, são algumas das formas de assimilação da complexidade de se debater currículo sob a perspectiva da teoria pós-crítica, que evidencia a necessidade de trabalhar temas como: identidade, diferenças, subjetividade, saber, poder, cultura, gênero, raça e multiculturalismo, por exemplo. Assim, a questão do debate (seja em gênero, cultura ou sexualidade) torna-se mais do que indispensável, visto que as problematizações vão além do que é padronizado em diretrizes educacionais.

\section{A padronização do currículo: por que é} tão difícil diversificar?

De acordo com Santos e PereiraDiniz (2016), em 1990 as Diretrizes
Curriculares Nacionais (DCN) e os Parâmetros curriculares Nacionais (PCN) foram duas iniciativas governamentais que promoveram mudanças na educação nacional. A primeira assegurava a formação da educação básica, por meio da união de Estados e municípios e Distrito Federal, onde a formulação do currículo escolar tivesse uma parte comum e uma diversificada. Nesta parte diversificada, estabelecia-se que cada município e escolas fossem responsáveis pela elaboração do plano de educação e propostas disciplinares para educação básica. Já os Parâmetros Curriculares Nacionais, adotados a partir de 1997 orientavam sobre o ensino de cada disciplina, onde as escolas poderiam propor sobre a elaboração de livros e materiais didáticos, o que levou grandes controvérsias e discussões sobre a comunidade acadêmica (SANTOS e PEREIRA-DINIZ, 2016).

De acordo com as DCNs (Diretrizes Curriculares Nacionais), as escolas têm autonomia para elaborar suas próprias propostas pedagógicas dentro do 


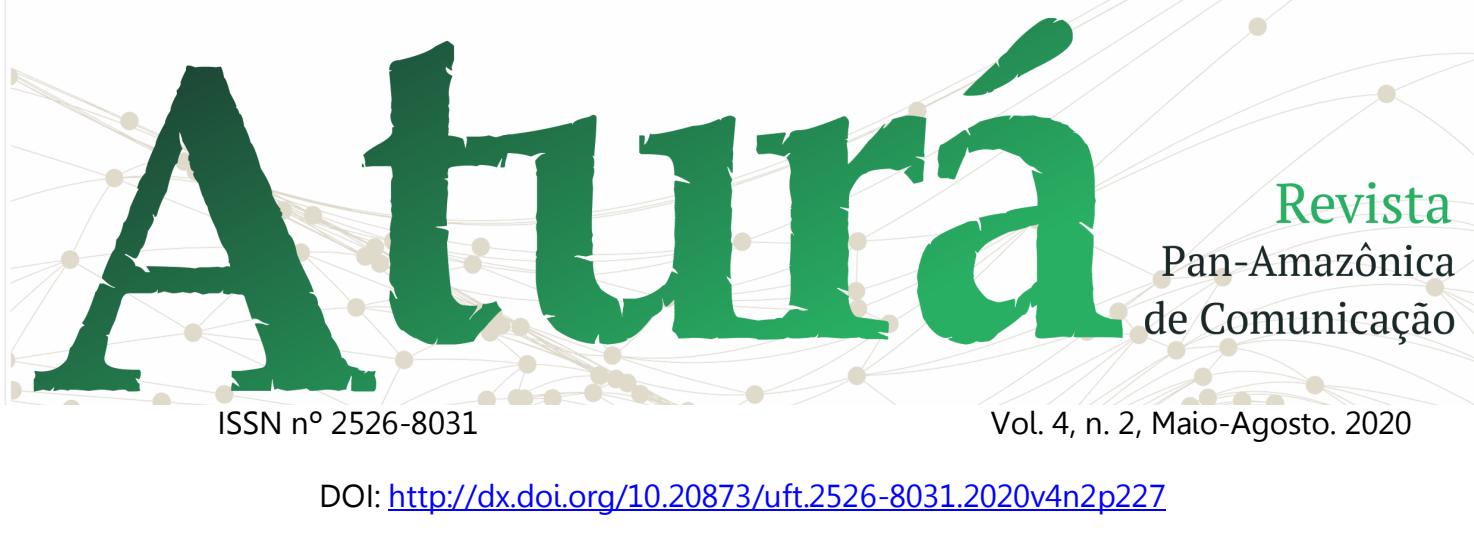

currículo, desde que as áreas de conhecimento e conteúdos tenham fundamentos e competências para o aluno (FERRAZ e CORREIA, 2012). Porém, o gargalo entre proposta e oportunidade para diversificação ainda é muito difícil de ser quebrado, uma vez que o debate na perspectiva diversa sobre a construção social do aluno como indivíduo social ainda é historicamente convencional.

De acordo com Arroyo (2015), as mudanças nos currículos devem acontecer de cima para baixo, ou seja, exigem estratégias de intervenção no Estado e posteriormente em suas instituições, uma vez que não há como fazer medicações sem análises moldadas, pois Ele - Estado - condena relações sociais e políticas na especificidade de nossa sociedade. Possivelmente a padronização do currículo, mesmo podendo ser reformulado, ainda é barrada pela expressão resistente da maioria da população, carregada de concepções ideológicas e até do próprio sistema escolar.
Para Arroyo (2015), todos têm direito de conhecer a história e ter consciência das mudanças que são sujeitos, entendo os processos formadores da produção de outras culturas, valores e conhecimentos por meio dos currículos e práticas pedagógicas. E ainda acrescenta que "os currículos não são apenas conteúdos organizados por boas teorias e intenções ideológicas, são grades estruturantes de conhecimentos e do trabalho docente que pressupõem uma base material, um sistema" (ARROYO, 2015, p. 03). Do mesmo modo, Ferraz e Correia (2012, p. 3) explicam que o currículo "é uma ação pedagógica coletiva que se fundamenta numa concepção de homem e de sociedade, implicando em atitudes frente às relações sociais e políticas".

A resistente padronização do currículo também apresenta outras limitações, como o controle do processo de ensino tradicional, que é direcionado a um ciclo produtivo, com objetivos específicos sobre qualidade e eficiência, desconsiderando a caracterização pessoal 


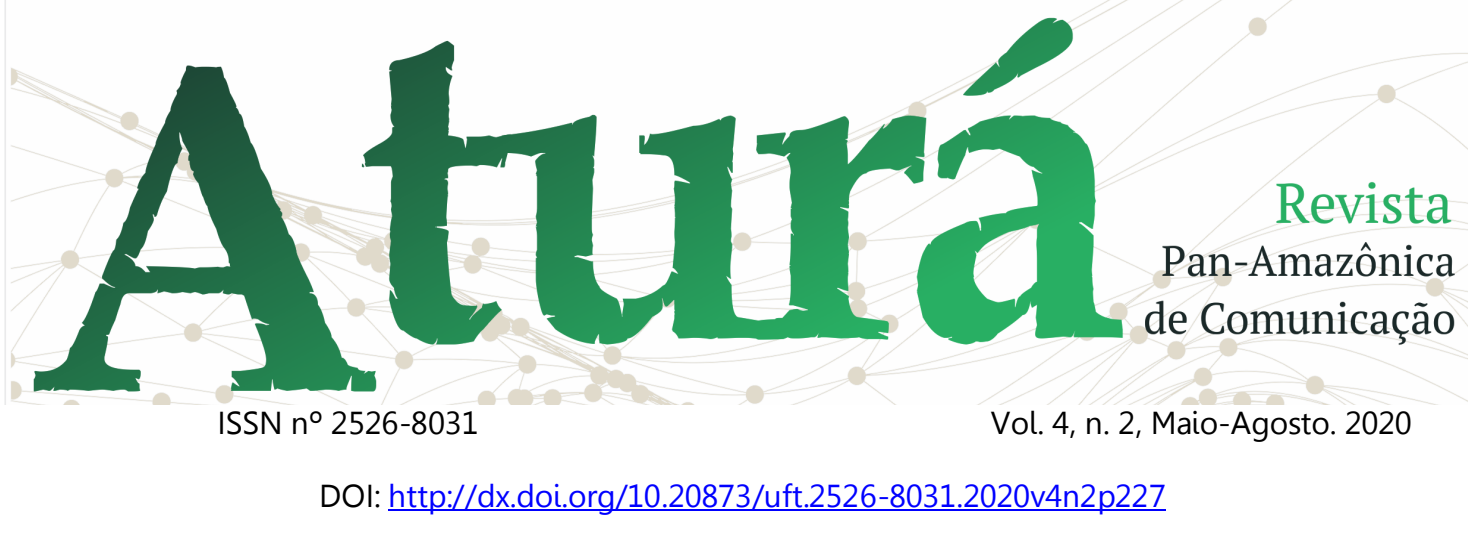

do ser como indivíduo social. Por isso Santos e Pereira-Diniz (2016, p. 02) consideram que "as padronizações submetem $O$ trabalho docente a determinações tomadas por técnicos e especialistas, desrespeitando a autonomia das escolas e de seus professores, a diversidade cultural dos alunos e seus ritmos de aprendizagem". A expressão de experiências e conhecimento é que cria bases para elaboração de um currículo diverso dentro da realidade em que estão inseridos os indivíduos sociais.

\section{Perspectivas de representatividade cultural, sexual e de gênero na educação básica}

Magalhães, Rocha e Damas (2009), discorrem que hoje é comum as organizações curriculares se basearem em uma modelo linear de disciplina, baseado na ciência do século XVII ao XX onde possibilitava o progresso acelerado de cada área do saber. Dessa forma, quando se trata de assuntos que aguçam 0 debate ideológico da maioria da sociedade, como sexualidade e gênero, as indagações vão muito além da perspectiva cultural e social, cujo determinismo natural vale mais que a construção social do homem.

A chamada Lei de Diretrizes e Bases - LDB n9.394/96 - sugere que sejam reconhecidas diferentes culturas, etnias e diversos grupos étnicos na formação da sociedade brasileira, fazendo com que a elaboração do currículo avance no reconhecimento das diferenças (ARROYO, 2015). Porém, existe muita resistência popular que sempre busca limitar a escola de ministrar aulas, palestras, oficinas e formações quando temas como a ideologia ou a teoria de gênero ganham foco.

Atos de resistência, muitas vezes, são reflexos do imaginário coletivo que trata o tópico como parte de um processo de disseminação da "imoralização" na sociedade, pensamento equivocado e infundado que limita as trocas e as aprendizagens dentro do ambiente escolar. $O$ destaque atual da 


\section{A \\ ISSN n² 2526-8031 \\ Vol. 4, n. 2, Maio-Agosto. 2020 \\ Revista \\ Pan-Amazônica \\ de Comunicação \\ DOI: http://dx.doi.org/10.20873/uft.2526-8031.2020v4n2p227}

ideologia de gênero faz com que o debate seja ainda mais complexo, uma vez que é visto como indulto ideológico que descontrola os papéis de gênero tradicionais, tornando a família um pânico moral e retrocesso, quando na verdade, apenas se trata de uma orientação sexual e promoção da igualdade social na escola (REIS; EGGERT, 2017). Do lado sexual, ao que tudo indica, mesmo com evolução social sobre essas concepções, o debate ainda é muito difícil, definido especialmente por grupos que tem a necessidade de manter valores mais conservadores de uma "cultura tradicional".

Nos dias de hoje, apesar da consolidação dos avanços sociais encabeçados pelos movimentos democráticos ocorridos nas últimas décadas, as desigualdades sociais ainda se fazem presentes no âmbito escolar e também para além das salas de aula. "As relações entre as distintas identidades culturais, assim como as tentativas, por partes de diferentes grupos, de afirmação e de representação em políticas e práticas sociais, são complexas, tensas, competitivas, imprevisíveis" (MOREIRA, 2002, p. 02).

A perspectiva cultural, sexual e de gênero trouxeram indagações importantes diante da construção social tradicional do ser que ainda existe hoje. A sociedade regulada pelo temor de enfatizar a discussão e a problematização em torno dessas perspectivas, reflete negativamente no estabelecimento reformas educacionais dos currículos, dentro da dita teoria pós-críticas. Como consequências, as propostas de diversificação do currículo escolar para essa linha se deparam em inúmeros questionamentos sociais regressistas, como "a natureza e a função de homem e mulher não podem ser diversificadas" e/ou "a escola não é lugar pra se discutir sexualidade".

Ao longo de anos temos acompanhado o conflito cultural e seus debates que levantam condições de poder a grupos dominantes sobre 


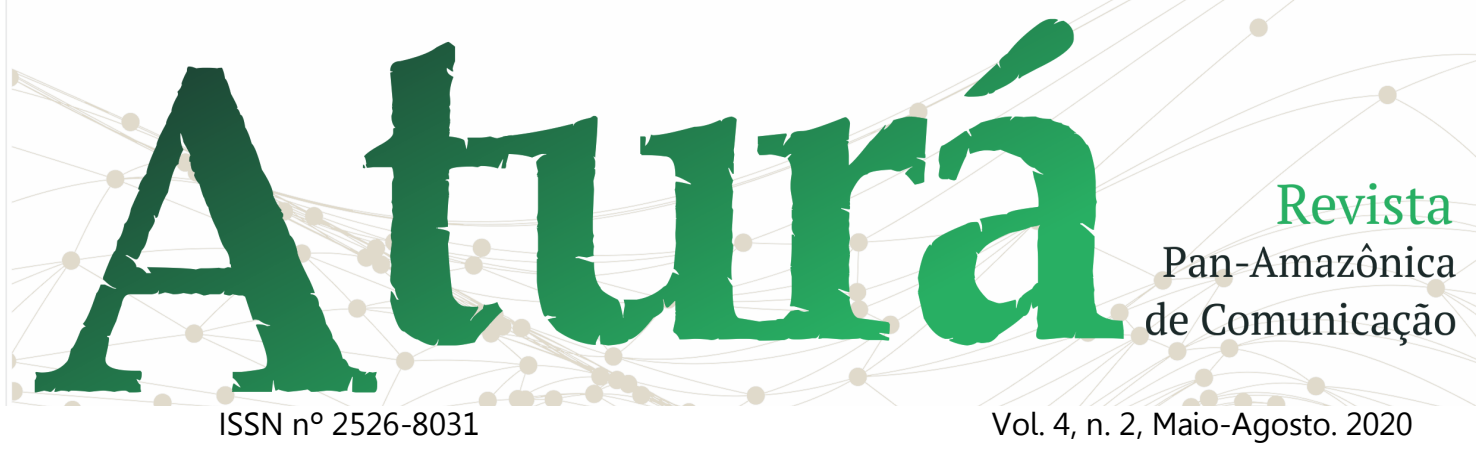

DOI: http://dx.doi.org/10.20873/uft.2526-8031.2020v4n2p227

aqueles que chamamos de minorias ${ }^{3}$. A exclusão e a discriminação são evidências do cenário de guerra (simbólica e até física) que assola o cotidiano social daqueles que querem reconhecimento além dos direitos e deveres assegurados pela legislação brasileira.

Em propostas de práticas e reformas educacionais, o currículo é uma das questões principais, pois, propicia espaços de luta para entre diferentes grupos, especialmente quando se passa para o pensamento pós-crítico, relacionado à luta de conflitos simbólicos e estudos multiculturais (RAIMANN, 2007). Talvez a base do discurso sobre currículo devesse ser mais abrangente e que tomasse posse de disciplinas onde seja possivel aprimorar as relações. Talvez pudesse ser analisado que a consciência de identidade, cultura, sexualidade e gênero são tão importantes para o ser

\footnotetext{
3"Minoria pode ser definida, a partir de uma particularização de um grupo, já que a maioria se define por um agrupamento generalizado, ou seja, por um processo de generalização baseado na indeterminação de traços, os quais indicam um padrão de suposta normalidade, considerada majoritária em relação ao outro que destoar dele." (CARMO, 2016, p. 205).
}

quanto outras áreas e conhecimento da sociedade, como a religião.

De acordo com Arroyo (2015) as mudanças nos currículos exigem estratégias de intervenção no Estado e, posteriormente, em suas instituições. Ele - Estado - condena relações sociais e políticas na especificidade de nossa sociedade. Possivelmente, a padronização do currículo, mesmo podendo ser reformulado, ainda é barrada pela expressão resistente da maioria da população, carregada de concepções ideológicas e até do próprio sistema escolar.

\section{Suporte teórico metodológico}

As metodologias utilizadas para realização deste estudo foram de ordem qualitativa, utilizando a pesquisa descritiva e por meio procedimento bibliográfico e documental. Na pesquisa documental foram analisados princípios pedagógicos e ideológicos inseridos dentro do Plano Municipal de educação, regidos conforme levantamento bibliográfico, elaborados em constructos 


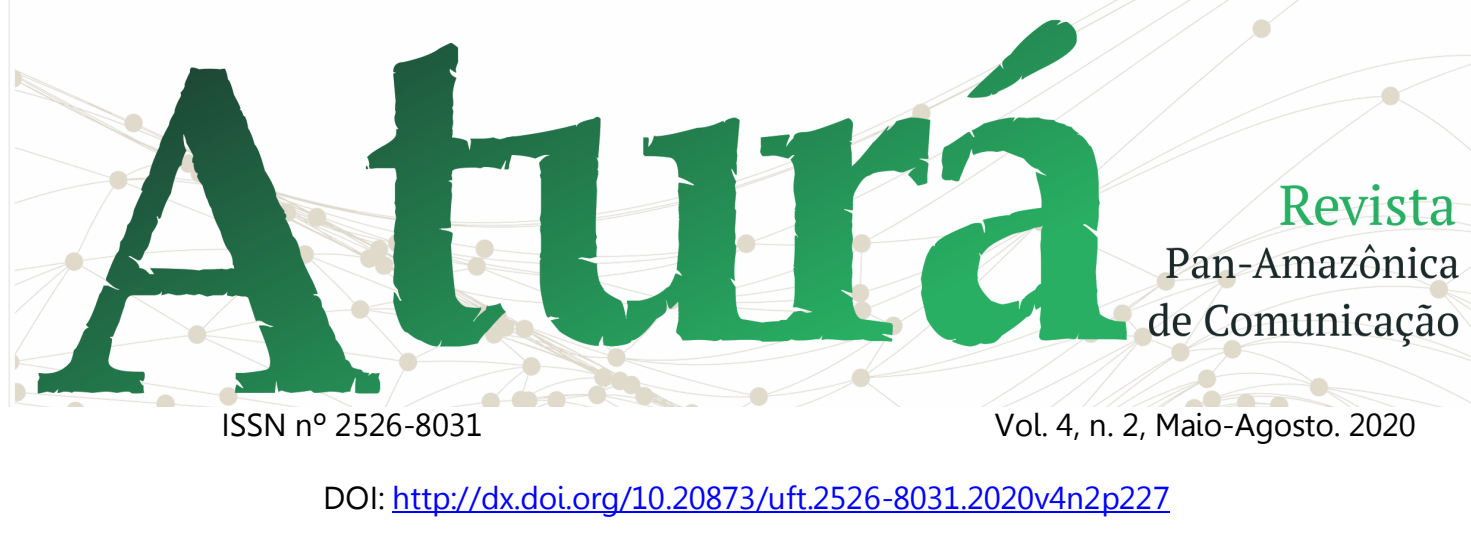

teóricos dentro dos seguintes eixos: (i) cultura; (ii) sexualidade e (iii) gênero.

O quadro teórico foi pautado sobre a premissa das teorias pós-críticas, difundida em uma das obras mais importantes sobre currículo, publicada por Tomaz Tadeu da Silva (1999), chamado "Documentos de identidade: uma introdução às teorias do currículo". Na concepção que se emprega o quadro teórico, se ver a contribuição de autores que defendem o multiculturalismo, diversidade cultural, sexual e de gênero, como forma de promoção de conhecimento das peculiaridades da sociedade e não como uma imposição ideológica superior.

\section{Resultados, análises e discussões}

Plano de educação municipal de Palmas-TO foi aprovado por meio da lei $n^{\circ} 2.238$, de 19 de janeiro de 2016 e alterado pelo Decreto $n^{\circ} 2.243$, de $23 / 03 / 2016$. O novo plano de educação define metas, estratégias e processo curricular para até 2025. Ao tocante de gênero é indispensável destacar que ao dia 15/03/2016 a câmara municipal de Palmas e o então Prefeito Carlos Amastha (PSB), aprovaram a proibição de livros que tratassem do tema sobre gênero no plano municipal de educação no município.

A sessão pautada de argumentos que destacavam os valores da família e o amadurecimento natural da criança sem interrupção da escola, a questão definitivamente não teve 0 debate profundo que naturalmente seria necessária uma análise expressiva sobre o assunto. Contudo, é importante destacar que ao dia 27 de agosto de 2018, o Ministro do Supremo Tribunal Federal (STF), Juíz Luiz Roberto Barroso, suspendeu os Artigos da Lei $n^{\circ} 2.238$, de 19 de janeiro de 2016, que proíbe o ensino sobre sexualidade e gênero nas escolas. Como argumento, o Ministro discorre que cabe a União discutir sobre a diretrizes de base da educação básica.

No Quadro teórico, analisamos contribuições que poderiam aguçar um debate expressivo diante da flexibilidade do currículo e da inclusão de temas 


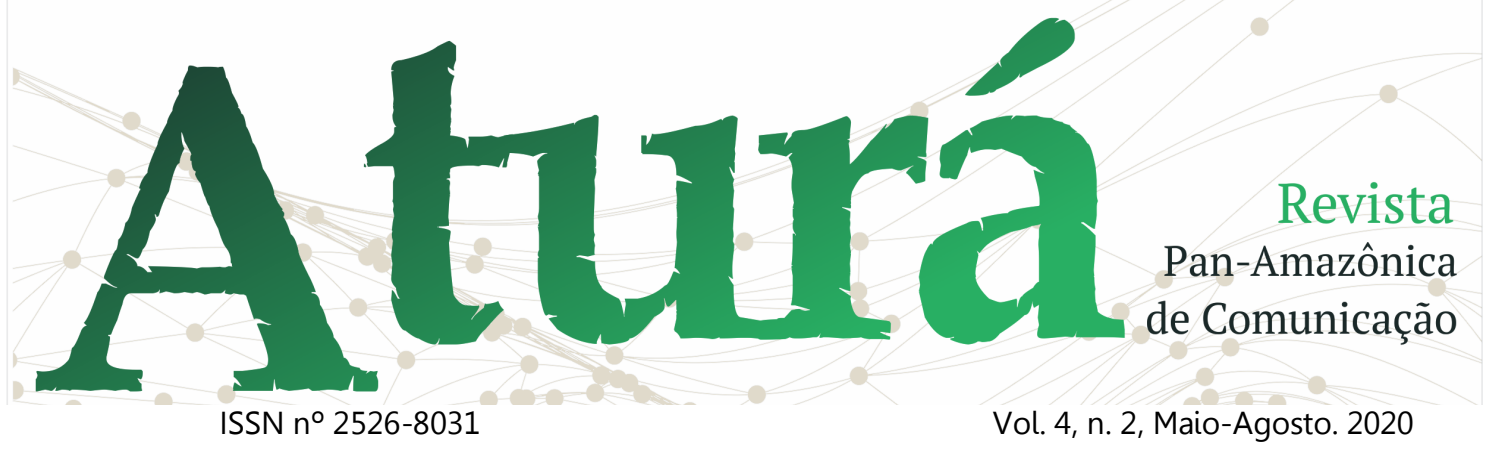

DOI: http://dx.doi.org/10.20873/uft.2526-8031.2020v4n2p227

transversais como diversidade cultural, sexual e de gênero.

Quadro 01 - Indagações teóricas do Plano de educação municipal de Palmas-TO

\begin{tabular}{|c|}
\hline SEXUALIDADE \\
\hline Estratégia 5.24 \\
\hline $\begin{array}{l}\text { Estabelece: [...] vedada à discussão [...], bem como os assuntos ligados à } \\
\text { sexualidade e erotização. } \\
\text { Indagação teórica: Notamos no texto que a sexualidade é popularmente associada } \\
\text { à erotização. No entanto, "a sexualidade remete, a uma série de crenças, } \\
\text { comportamentos, relações e identidades sociais historicamente construídas" } \\
\text { (FELIPE, 2006, p. 258). Foucault (1988) escreve que do século XIX até então a } \\
\text { sexualidade ganha forma de múltiplas perversões. Dessa forma, Do Nascimento } \\
\text { (2016) explica que, a sexualidade pode até ser, mas não é vista como uma temática } \\
\text { que vislumbra o conhecimento sobre o sexo e os riscos eminentes, ou como uma } \\
\text { educação sexual efetiva. }\end{array}$ \\
\hline GÊNERO \\
\hline Estratégia 5.24 \\
\hline $\begin{array}{l}\text { Estabelece: [...] vedada à discussão e a utilização de material didático e } \\
\text { paradidático sobre a ideologia ou teoria de gênero inclusive promoção e condutas, } \\
\text { permissão de atos e comportamentos que induzam à referida temática. } \\
\text { Indagação teórica: Ideologia e teoria de gênero são limitadas ao debate na } \\
\text { educação básica por defenderem, na maioria das vezes, por meio de preceitos } \\
\text { religiosos, que podem induzir comportamentos e atos relacionados à sexualidade } \\
\text { e erotização (LIONÇO, 2018). Diferente do que trata a biologia, a ideologia de } \\
\text { gênero toma parte de um espaço de poder de lutas, enquanto sexualidade não se } \\
\text { limita a prática sexual, mas sim, outros elementos que constroem a sexualidade } \\
\text { (MAIA; ROCHA; VIZOLLI, 2017). O feminismo, por exemplo, como forma de luta na } \\
\text { construção de igualdade social e de gênero tenta destruir a desigualdade que } \\
\text { muito resulta em violência contra mulheres (ALECRIM, 2017). }\end{array}$ \\
\hline CULTURA \\
\hline Estratégias 5.25 e 5.26 \\
\hline $\begin{array}{l}5.25 \text { - Estabelece: [...] garantir a oferta da educação do campo garantindo que ela se } \\
\text { efetive considerando o desenvolvimento sustentável, a preservação da identidade } \\
\text { cultural [grifo nosso], a participação da comunidade na definição do modelo de } \\
\text { organização pedagógica e de gestão das instituições, as práticas socioculturais e as } \\
\text { formas particulares de organização do tempo e do espaço [...]. } \\
\text { Indagação teórica: Identidade e cultura são acepções que sempre passam por }\end{array}$ \\
\hline
\end{tabular}




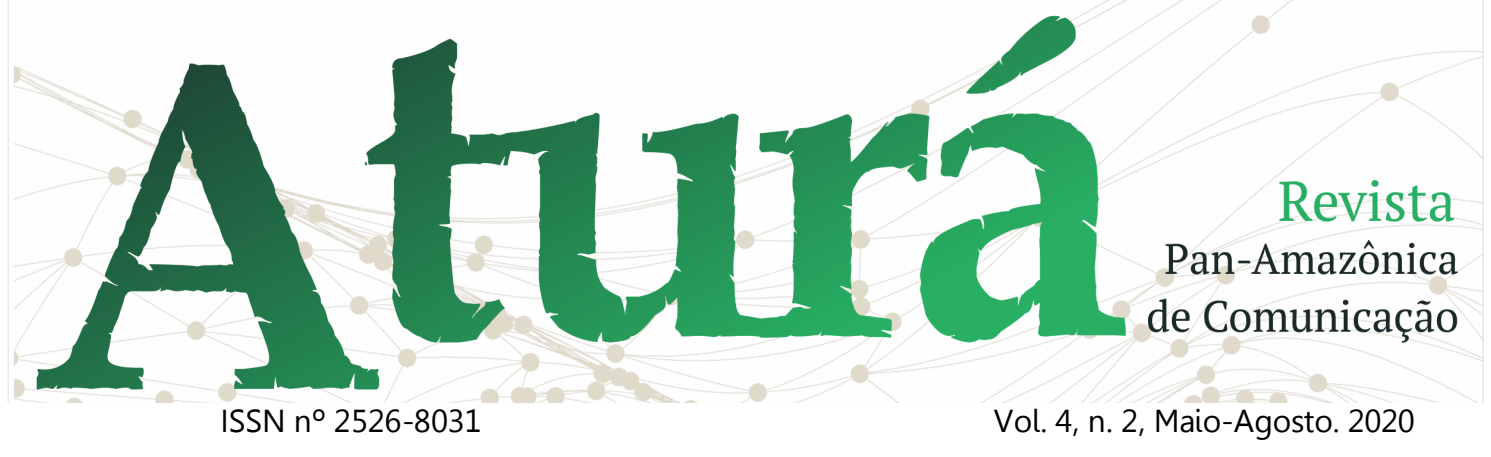

DOI: http://dx.doi.org/10.20873/uft.2526-8031.2020v4n2p227

conflitos, mudanças, normas sociais e é "cultural tudo que é produto de escolhas humanas" (MAIA; ROCHA; VIZOLLI, 2017, p. 156). Uma forma de preservar a identidade cultural é respeitar os conflitos e mudanças que se instauram na sociedade. Educação de direitos humanos também está ligado à cultura e diversidade, mais especificamente Bhabha (2007) afirma em seus estudos que o gênero é uma prerrogativa cultural.

5.26 - Estabelece: "[...] assegurar a oferta de formação continuada específica e a inclusão transversal, para que as formações considerem temáticas relativas à educação ambiental, à diversidade cultural, às relaçôes étnico-raciais [grifo nosso] $[\ldots]^{\prime \prime}$.

Indagação teórica: Compreende-se que, diversidade cultural se relaciona com outros grupos sociais da sociedade. Da Silva (1999) esclarece que as relações étnico-raciais são outras prerrogativas, que além de gênero e sexualidade são elementos que reforçam a luta pela desigualdade social. A diversidade múltipla faz parte da humanidade e a escola tem como princípio mostrar que apoia as diferentes culturas (FERNANDES, 2005).

Meta 14.

Estratégia 14.4 - Estabelece: Fomentar estudos e pesquisas que analisem a necessidade de articulação entre formação, currículo, pesquisa e mundo do trabalho, considerando as necessidades econômicas, sociais e culturais do município de Palmas [grifo nosso] [...].

Indagação teórica: Necessidades culturais e sociais são perspectivas que abrangem as teorias pós-críticas apresentadas nos estudos de Da Silva (1999), uma vez que defende, inclusive de maneira abrangente, o multiculturalismo como forma de luta política e reconhecimento de todos os grupos. Se o currículo busca considerar as necessidades culturais e sociais do município, automaticamente considera toda uma esfera de prerrogativas sociais e culturais já supracitadas.

Fonte: Plano de Educação do Município de Palmas-TO (2015), alterado pelo Decreto n 2.243, de 23/03/2016 (2016), com indagação de vários autores.

Através do quadro é possível elucidar que existe um desencontro, entre as acepções teóricas e o texto do Plano de Educação, assim como há também um desencontro do próprio texto para com seus fragmentos. O texto aparentemente transdisciplinar, arraigado de discursos que prezam pelo indivíduo, pela liberdade, diversidade, diferenças e o multiculturalismo, na verdade expressa em análises mais profundas e controvérsias, um significado ainda muito comum nos moldes das teorias tradicionais. 


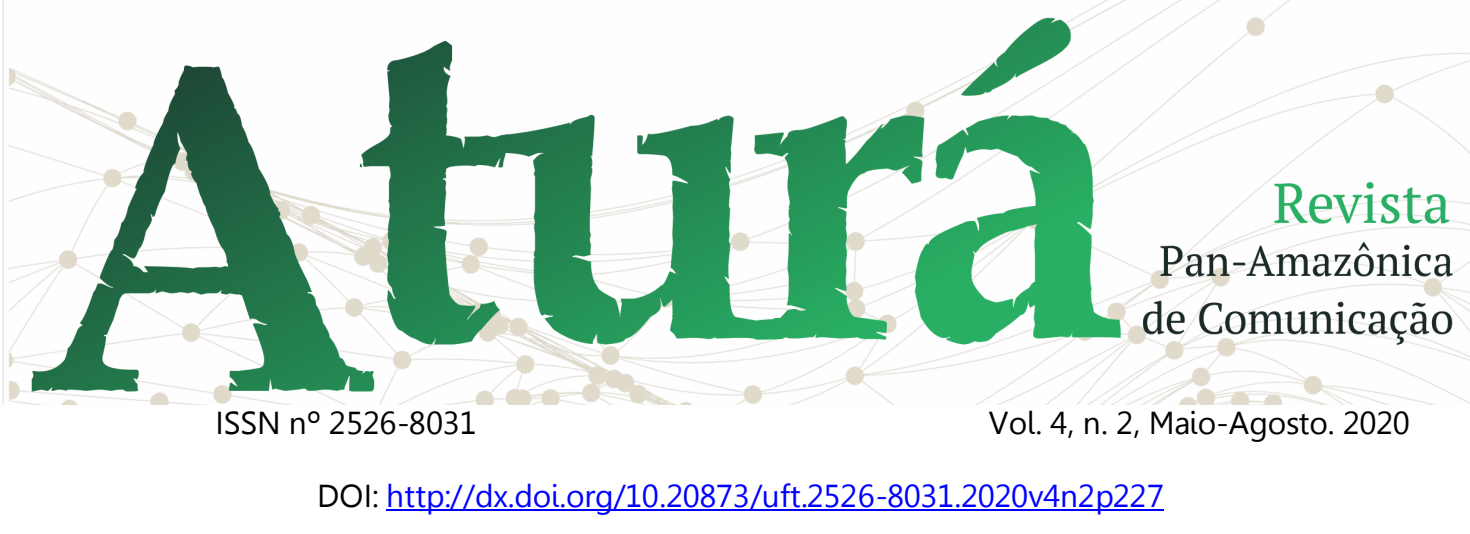

A livre expressão sobre os debates, em primeira face escancarada, na verdade ganha limitações à medida que se avalia os fragmentos conceituais. As relações, por exemplo, no fim de tudo, não são contempladas à realidade de uma narrativa ética sobre o espaço de expressão, onde haja explanação sobre as visões estruturais da contemporaneidade, da diversidade e multiculturalismo, há sim, uma deterioração de interpretação conceitual dos significados.

\section{Considerações finais}

Por meio do estudo foi possível verificar, até onde a teoria e aplicabilidade se (des) encontram no currículo do município de Palmas-TO. Há conflitos no texto quando se tenta defender a prerrogativa cultural, e o apoio às diferenças. A sexualidade, por exemplo é documentada e popularmente associada a erotização, sendo que a temática parte de princípios mais complexos e distintos dos que as informações geradas pelo senso comum da sociedade. A questão da sexualidade já saiu de centralidade de discussão, desde o século XVII com o poder de desassociação da Igreja (FOUCAULT, 1988), por ser considerado "imoral".

A discussão sobre gênero é limitada ao debate por estar associada a construção de múltiplas sexualidades na sociedade, sem considerar as forças políticas e sociais dos movimentos feministas no Brasil e no mundo. Gênero não é sexualidade. Gênero é uma construção identitária e o texto curricular não dá visibilidade a isso, ao contrário, faz confusão.

Ao se referir sobre a cultura, vemos no currículo uma desassociação do significado social da palavra, onde é tratado como relevante, contudo, descentralizado quando voltado para lógica do multiculturalismo, defendido dentro da teoria pós-crítica que se releva na sociedade atual de múltiplas diversidades.

É importante frisar que desde de 1997 existem evidências sobre a 


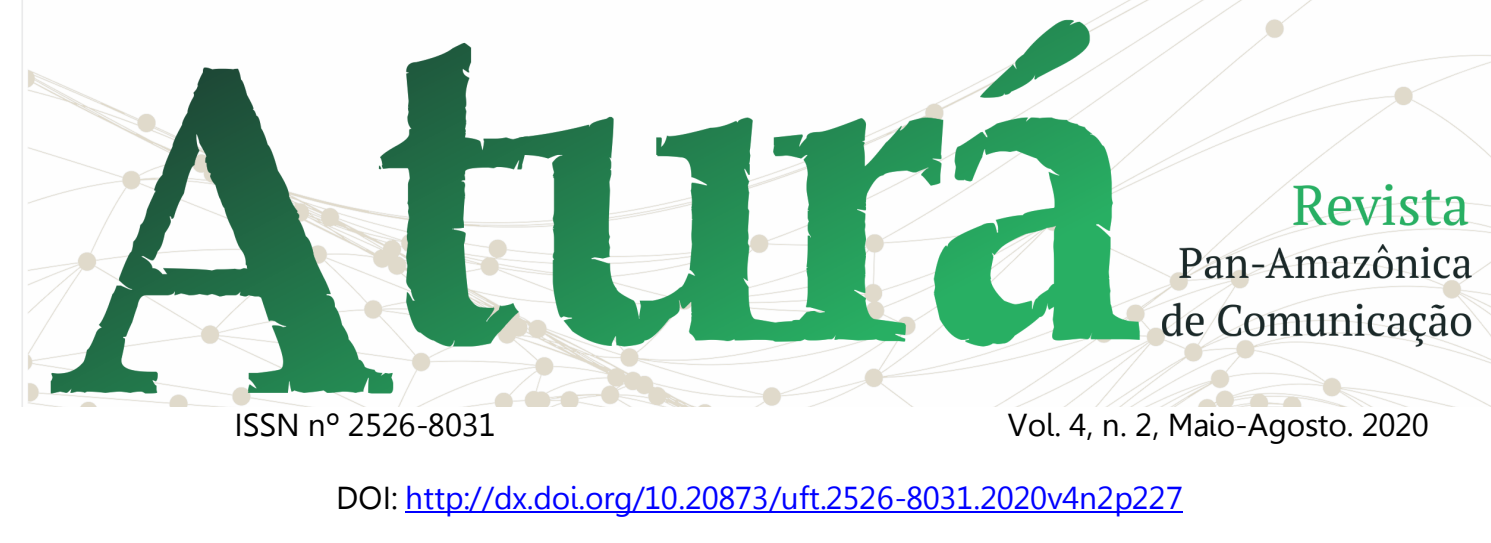

pluralidade cultural e orientação sexual nos documentos curriculares de educação com o lançamento dos Parâmetros Nacionais de Educação (PCNS) pelo Governo Federal. Observa-se nessa máxima que mesmo estando dentro dos parâmetros educacionais, o debate sobre os temas transversais aqui tratados ainda passa por resistências dentro do currículo regular. Dentro do currículo oculto, que trata de assuntos que não são planejados, mas difundidos por meio da vivência dos professores (PERRENOUD, 1996) é que ainda se ver a discussão de temas transversais, como multiculturalismo, diversidade cultural, sexual e gênero. Por esse contexto, que os aspectos de formação do currículo devem ser propostos a partir de questões relacionadas à realidade da sociedade e em diferentes contextos, ou seja, deve ser diversificado.

\section{Referências}

ALECRIM, Edisselma dos Santos. Discussão de Gênero no Plano Municipal de Educação de palmas -TO. Seminário Internacional Fazendo Gênero 11 \& 13th
Women's Worlds Congress. Anais Eletrônicos...Florianópolis, 2017.

ARROYO, Miguel G. Os Movimentos Sociais e a construção de outros currículos. Educar em Revista, Curitiba, Brasil, n. 55, p. 47-68, jan./mar. 2015.

BHABHA, Homi. O local da cultura. Belo Horizonte: Editora UFMG, 2007.

BRASIL. Lei $n^{\circ}$. 9.394, de 20 de dezembro de 1996. Estabelece as diretrizes e bases da educação nacional. Diário Oficial da União. Brasília, 1996.

BRASIL. Conselho Nacional de Educação. Diretrizes Curriculares Nacionais para o ensino fundamental de nove anos. Brasília: CNE, 2010.

CARMO, Cláudio Márcio do. Minority groups, vulnerable groups and the problem of (in)tolerance: a linguisticdiscursive and ideological relationship between disrespect and the manifestation of hatred in the Brazilian contexto. Revista do Instituto de Estudos Brasileiros, n. 64, p. 201-223, 2016.

DA SILVA, Tomaz Tadeu. Documentos de identidade: uma introdução ás teorias do currículo. Belo Horizonte: Autentica, 1999.

DO NASCIMENTO, Maria do Socorro. Sexualidades e currículo: quem tem medo dessa relação? Reb. Revista De Estudios Brasileños I, v. 3, n. 5, 2016. 


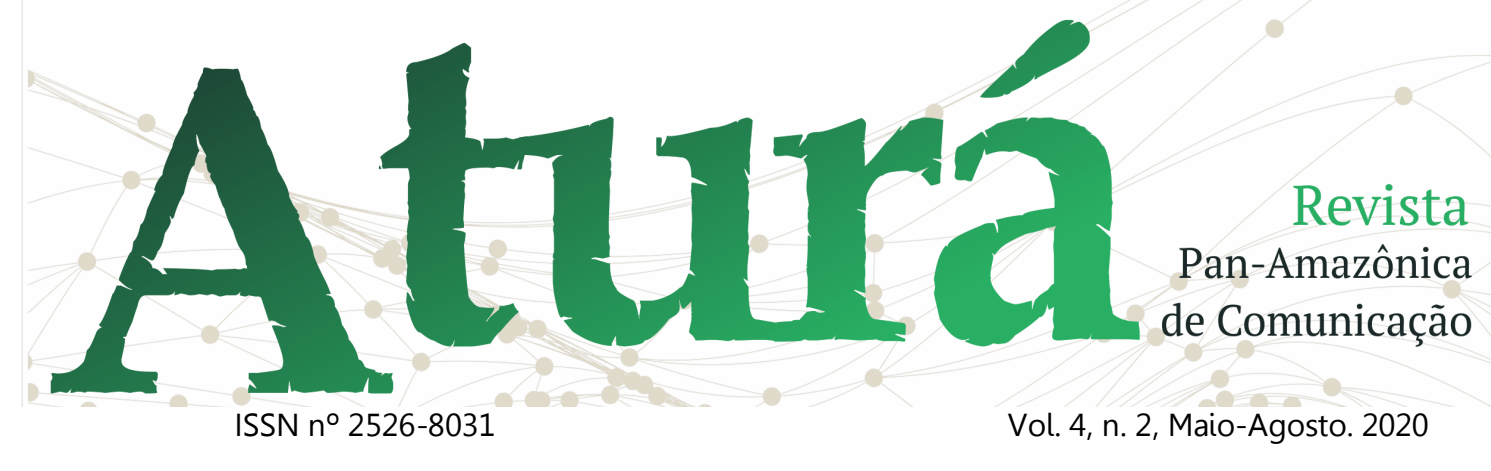

DOI: http://dx.doi.org/10.20873/uft.2526-8031.2020v4n2p227

FELIPE, Jane. Representações de gênero, sexualidade e corpo na mídia. Tecnologia e Sociedade, v. 2, n. 3, p. 251-263. 2006.

FERNANDES, José Ricardo Oriá. Ensino de história e diversidade cultural: desafios e possibilidades. Cad. Cedes, Campinas, v. 25, n. 67, p. 378-388, set./dez. 2005.

FERRAZ, Osvaldo Luiz; CORREIA, Walter Roberto. Teorias curriculares, perspectivas teóricas em Educação Física Escolar e implicações para a formação docente. Revista brasileira de Educação Física e Esporte, São Paulo, v.26, n.3, p.531-40, jul./set. 2012.

FOUCAULT, Michel. História da sexualidade: A vontade de saber. Tradução: Maria Thereza da Costa Albuquerque e J. A. Guilhon Albuquerque. Rio de Janeiro: Edições Graal, 1988.

LIONÇO, Tatiana et al,. Ideologia de gênero: estratégia argumentativa que forja cientificidade para o fundamentalismo religioso. Psicologia Política, v. 18, n. 43, p. 599-621, 2018.

MAGALHÃES, Hilda Gomes Dutra; ROCHA, José Damião Trindade; DAMAS, Luiz Antônio Hunold de Oliveira. O currículo como vivência da complexidade no espaço escolar. Educação Temática Digital, Campinas, v.11, n.1, p.35-51, jul./ dez. 2009.

MAIA, Macos Felipe Gonçalves; ROCHA, Damião; VIZOLLI, Idemar. identidade cultural, diversidade e diferença: um olhar para gênero e sexualidade na educação. Cad. Ed. Tec. Soc., Br. J. Ed., Tech. Soc., v. 10, n. 2, p. 153-167, 2017.

MOREIRA, Antonio Flavio Barbosa. Currículo, diferença cultural e diálogo. Educação \& Sociedade, Rio de Janeiro. n. 79, 2002.

PERRENOUD, P. La construcción del êxito y del fracaso escolar. Madrid: Morata, 1996.

PALMAS - TO. Lei Municipal $\mathrm{n}^{\circ}$ 2.243/2016, de 23 de março de 2016. Disponível em: https://legislativo.palmas.to.gov.br/media /leis/lei-ordinaria-2.243-2016-03-23-3-62016-15-41- 30.pdf Acesso em 25 jun. 2019.

PALMAS - TO. Lei no 2.238, de 19 de janeiro de 2016 - Plano Municipal de Educação de Palmas - TO. Diário Oficial de Palmas - TO, 19 jan. 2016. Acesso em 04 jul. 2019.

RAIMANN, Elizabeth Gottschalg. O currículo e a educação de jovens e adultos: espaço de poder-saber. Revista Acolhendo a Alfabetização nos Países de Língua portuguesa, São Paulo, v. 2, n. 3, 2007.

REIS, Toni; EGGERT, Edla. Ideologia de gênero: uma falácia construída sobre os planos de educação brasileiros Educ. Soc., Campinas, v. 38, n. 138, p.9-26. 2017. 


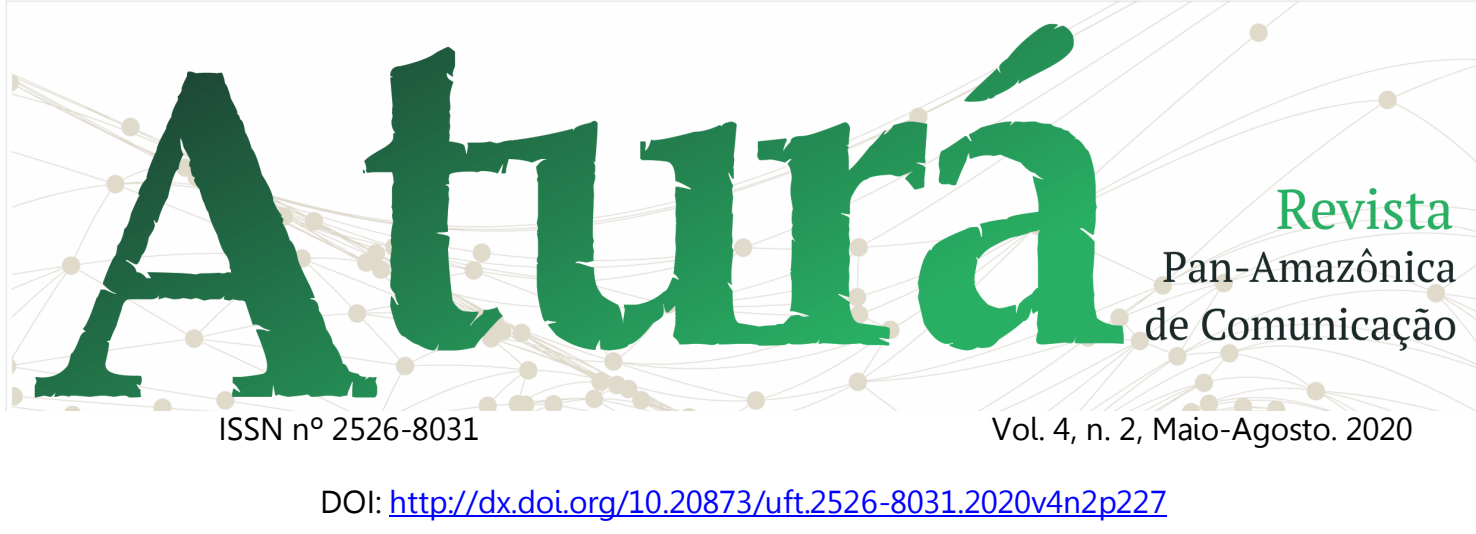

SANTOS, Lucíola Licínio de Castro Paixão; PEREIRA-DINIZ, Júlio Emílio. Tentativas de padronização do urrículo e da formação de professores no Brasil. Cad. Cedes, Campinas, v. 36 , n. 100 , p. 281-300, set.dez. 2016. 